\title{
HUBUNGAN ORIENTASI DENGAN TINGKAT KECEMASAN PASIEN DI RUANG PERAWATAN ANGGREK LANTAI II RSUD POLEWALI MANDAR
}

\author{
Andan Firmansyah, Rusman \\ LPPM STIKES Bina Generasi Polewali Mandar, JI. Mr. Muh yamin Manding, Polewali Mandar, \\ Sulawesi Barat email: Ippm@biges.ac.id
}

\begin{abstract}
Abstrak
Pasien yang masuk rumah sakit sering mengalami kecemasan dari kecemasan tingkat ringan sampai berat. Hal ini diduga perawat belum melaksanakan orientasi secara optimal. Pasien sering bertanya tidak tahu tempat pelayanan dan prosedur tindakan yang akan dilaksanakan, sebaliknya pasien yang mendapat penjelasan menunjukkan respon yang positif. Namun sampai saat ini belum diketahui pengaruh orientasi terhadap tingkat kecemasan. untuk mengetahui Hubungan Orientasi dengan Tingkat Kecemasan Pasien di Ruang Perawatan Anggrek Lantai II RSUD Polewali Mandar. Jenis penelitian ini adalah Cross Sectional Study. Populasi dalam penelitian ini adalah semua pasien yang menjalani pengobatan atau sedang dirawat inap di ruang Perawatan Anggrek Lantai II RSUD Polewali Mandar yaitu sebanyak 520 orang pasien pada tahun 2013 dengan sampel yang didapatkan sebanyak 35 orang. menunjukkan bahwa ada hubungan orientasi dengan tingkat kecemasan pasien di ruang perawatan anggrek lantai II dengan nilai uji statistik fisher's exact test diperoleh nilai $p=0,027<\alpha \quad 0,05$ maka dapat disimpulkan bahwa Ha diterim Perlu memotivasi perawat yang jaga agar melaksanakan prosedur tetap terhadap kegiatan orientasi pada semua pasien yang baru masuk rumah sakit. Hendaknya melaksanakan prosedur tetap program orientasi kepada setiap pasien baru sesuai dengan prosedur, sehingga pelaksanaan orientasi dapat optimal dan terjadi penurunan tingkat kecemasan pasien.
\end{abstract}

Kata Kunci : Orientasi, Kecemasan

Patients who entered the hospital often experience anxiety from mild to severe levels of anxiety. It is presumed nurses have not done in an optimal orientation. Patients are often asked did not know where services and procedures actions to be implemented, otherwise patients who briefed showed a positive response. But until now unknown orientation influence on the level of anxiety. The purpose of this study was to determine the orientation relationship with Anxiety Levels in Patients Orchid Lounge Second Floor Care Hospital Polewali. This research is a Cross Sectional Study. The population in this study were all patients undergoing treatment or are hospitalized in a room Floor II Orchid Care Hospital Polewali as many as 520 patients in 2013 with a sample obtained as many as 35 people. The results showed that there was a relationship orientation with the anxiety levels of patients in the treatment room floor II orchids to the value of the test statistic obtained Fisher's exact test $p=0.027<\alpha 0.05$ it can be concluded that $\mathrm{Ha}$ is accepted. Need to motivate nurses who keep carrying out the procedure remains the orientation activities in all patients newly admitted to the hospital. Should carry out the procedure fixed orientation program for every new patient in accordance with the procedures, so that the implementation can be optimized orientation and decrease patient anxiety levels.

Keywords: Orientation, Anxiety 


\section{PENDAHULUAN}

$\begin{array}{ccc}\text { Dalam } & \text { praktek } & \text { keperawatan } \\ \text { profesional } & \text { perawat memegang }\end{array}$ tanggung jawab yang sangat besar, dimana perawat dituntut untuk melaksanakan perannya selama 24 jam berada di samping pasien dan keluarganya. Pasien bersama keluarganya yang masuk rumah sakit (MRS) akan mengalami perasaan cemas atau yang sering disebut anxietas. Pada saat masuk rumah sakit pasien dihadapkan pada situasi baru, yaitu tenaga kesehatan dan klien lain, situasi ruang dan lingkungan rumah sakit, tindakan-tindakan yang dilakukan oleh tenaga kesehatan terhadap pasien, peraturan-peraturan rumah sakit yang berbeda dengan kebiasaan klien di rumah. Faktor tersebut dapat menimbulkan kecemasan bagi pasien, terutama yang belum pernah masuk rumah sakit.

Pasien yang masuk Rumah Sakit sering mengalami kecemasan dari kecemasan tingkat ringan sampai berat. Hal ini diduga perawat belum melaksanakan orientasi secara optimal. Pasien sering bertanya tidak tahu tempat pelayanan dan prosedur tindakan yang akan dilaksanakan, sebaliknya pasien yang mendapat penjelasan menunjukkan respon yang positif. Namun sampai saat ini belum diketahui hubungan orientasi terhadap tingkat kecemasan.

Menurut Arline Matthews (2007) pasien baru yang tidak di orientasikan akan mengalami cemas yang ditunjukkan oleh perilaku sering bertanya atau tidak bertanya sama sekali, sukar tidur, marah, tingkah laku mencari perhatian, kecemasan juga biasanya memhubungani cara orang menyerap apa yang sedang disampaikan. Berdasarkan konsep psikoneuroimunologi kecemasan merupakan stressor yang dapat menurunkan sistem imunitas tubuh. Imunitas tubuh yang menurun menyebabkan penyembuhan klien lama, dan biaya perawatan meningkat (Putra,ST, 2004).

Sebagian besar pasien masuk ke Rumah Sakit dengan persiapan atau sudah direncanakan, dimana klien sudah mempersiapkan segala sesuatu yang berhubungan dengan keperluan keperluan selama dirawat di Rumah Sakit. Tetapi sebagian besar klien masuk tanpa persiapan dan tanpa perencanaan sebelumnya atau masuk ke Rumah Sakit dalam keadaan darurat. Meskipun demikian dengan cara apapun klien masuk Rumah sakit ia akan merasa takut dan cemas. Fenomena seperti ini bagi perawat adalah hal yang biasa, tetapi bagi klien dan keluarganya merupakan hal yang menakutkan dan aneh. Oleh karena itu menerima pasien baru perlu dilakukan orientasi (Arline Matthews, 2007).

Dalam konteks keperawatan orientasi berarti mengenalkan segala sesuatu tentang Rumah Sakit meliputi lingkungan Rumah Sakit, tenaga kesehatan, peraturan, prosedur dan pasien lain. Perawat dan klien bekerja sama untuk menganalisa situasi sehingga mereka dapat mengenali, memperjelas dan menentukan eksistensi sebuah masalah. Sehingga diharapkan dapat mengurangi kecemasan klien dan keluarga, klien 
dapat bersosialisasi dengan lingkungannya (Bauwhuizen, 2006).

Pasien yang masuk rumah sakit sering mengalami kecemasan dari kecemasan tingkat ringan sampai berat. Hal ini diduga perawat belum melaksanakan orientasi secara optimal. Pasien sering bertanya tidak tahu tempat pelayanan dan prosedur tindakan yang akan dilaksanakan, sebaliknya pasien yang mendapat penjelasan menunjukkan respon yang positif. Namun, sampai saat ini belum diketahui hubungan orientasi terhadap tingkat kecemasan.

Sebagian besar klien masuk tanpa persiapan dan tanpa perencanaan sebelumnya atau masuk ke ruang interna dalam keadaan darurat. Oleh karena itu menerima penderita baru perlu dilakukan orientasi faktor tersebut dapat menimbulkan kecemasan bagi pasien, terutama yang belum pernah masuk rumah sakit (Carline Matthews, 2007).

Berdasarkan survey di lapangan yang dilakukan oleh peneliti pasien yang masuk rumah sakit sering mengalami kecemasan dari kecemasan tingkat ringan sampai berat, hasil studi pendahuluan yang dilaksanakan oleh peneliti di ruang perawatan anggrek lantai II RSUD Polewali Mandar, dari 10 pasien dimana menunjukkan pasien yang masuk rumah sakit mengalami tingkat kecemasan ringan 3 orang $(30 \%)$, sedang 2 orang $(20 \%)$ dan berat sebanyak 5 orang (50\%).

Hal ini diduga perawat belum melaksanakan orientasi secara optimal. Pasien sering bertanya tidak tahu tempat pelayanan dan prosedur tindakan yang akan dilaksanakan, sebaliknya pasien yang mendapat penjelasan menunjukkan respon yang positif. Namun sampai saat ini belum diketahui hubungan orientasi terhadap tingkat kecemasan.

Berdasarkan data yang diperoleh dari RSUD Polewali, tercatat jumlah pasien rawat inap di rungan perawatan anggrek lantai dua pada tahun 2011 tercatat 455 pasien, sedangkan pada tahun 2012 tercatat jumlah pasien sebanyak 467. Jumlah pasien yang dirawat pada tahun 2013, dari bulan januari sampai okrober 2013 jumlah pasien di ruang perawatan anggrek lantai dua sebanyak 520 pasien dimana laki-laki 343 orang (57\%) dan perempuan sebanyak 177 orang (43\%). Data tiga bulan terakhir pada bulan september 35 orang, oktober 40 orang dan november 38 orang.

Berdasarkan hal tersebut di atas peneliti tertarik untuk mengadakan penelitian tentang "Hubungan Orientasi dengan Tingkat Kecemasan Pasien di Ruang Perawatan Anggrek Lantai II RSUD Polewali Mandar".

\section{METODE PENELITIAN}

Metode atau desain yang digunakan dalam penelitian ini adalah desain penelitian cross sectional yang meruapakan rancangan penelitian yang pengukuran atau pengamatannya dilakukan secara simultan pada satu saat (sekali waktu).

Populasi dalam penelitian ini adalah semua pasien yang menjalani pengobatan atau sedang dirawat inap di ruang Perawatan Anggrek Lantai II RSUD Polewali Mandar yaitu sebanyak 520 orang pasien pada tahun 2013. 
Sampling adalah suatu proses dalam menyeleksi porsi dan populasi untuk dapat mewakili populasi (Nursalam, 2011). Penelitian ini menggunakan Non Probability sampling (Aksidental Sampling) yaitu pengambilan sampel secara aksidental yang dilakukan dengan mengambil kasus atau responden yang kebetulan ada atau tersedia. Bedanya dengan purposive sampling adalah, kalau sampel yang diambil secara pusposive berarti dengan sengaja mengambil atau memilih kasus atau responden. Sedangkan sampel yang diambil secara aksidental berarti sampel diambil dari responden atau kasus yang kebetulan ada (Wahab, 2012).

\section{HASIL PENELITIAN DAN PEMBAHASAN Analisa Univariat}

1. Umur Responden

Berikut ini distribusi responden berdasarkan umur pasien yang dirawat di Ruang Perawatan Anggrek Lantai II RSUD Polewali Mandar dapat dilihat pada tabel berikut :

Tabel. Distribusi responden berdasarkan umur

\begin{tabular}{|c|c|c|c|}
\hline No. & Umur Responden & $(\mathrm{n})$ & $(\%)$ \\
\hline 1 & $21-30$ thn & 16 & 45.7 \\
\hline 2 & $31-40$ thn & 2 & 5.7 \\
\hline 3 & $41-50$ thn & 6 & 17.1 \\
\hline 4 & $>51$ thn & 11 & 31.4 \\
\hline & Total & 35 & 100.0 \\
\hline
\end{tabular}

Sumber : Data Primer 2014

Berdasarkan tabel diatas didapatkan bahwa distribusi responden berdasarkan umur responden, yang paling tinggi terdapat pada umur 21-30 tahun sebanyak $16(55,7 \%)$ orang, pada umur $>51$ tahun sebanyak $11 \quad(31,4 \%)$ orang, pada umur 41-50 tahun sebanyak $6(17,1 \%)$ orang dan yang paling rendah terdapat pada umur 31-40 tahun sebanyak $2(5,7 \%)$ orang.
2. Jenis Kelamin Responden

Berikut ini distribusi responden berdasarkan jenis kelamin pasien yang di rawat di ruang Perawatan Anggrek Lantai II RSUD Polewali Mandar tahun 2014 dapat dilihat pada tabel berikut :

Tabel Distribusi responden berdasarkan jenis kelamin

\begin{tabular}{|c|c|c|c|}
\hline No. & Jenis kelamin & $(\mathrm{n})$ & $(\%)$ \\
\hline 1 & Laki - Laki & 15 & 42.9 \\
\hline 2 & Perempuan & 20 & 57.1 \\
\hline & Total & $\mathbf{3 5}$ & $\mathbf{1 0 0 . 0}$ \\
\hline
\end{tabular}

Sumber : Data Primer 2014

Berdasarkan tabel diatas didapatkan bahwa distribusi responden berdasarkan jenis kelamin responden, yang paling banyak yaitu jenis kelamin perempuan sebanyak 20 (57,1\%) orang dan sedikit pada laki-laki yaitu sebanyak $15(42,9 \%)$ orang. 
Berdasarkan Tingkat Pendidikan Berikut ini ini distribusi responden berdasarkan tingkat pendidikan pasien yang di rawat di ruang Perawatan Anggrek Lantai II RSUD Polewali Mandar tahun 2014 dapat dilihat pada tabel berikut

Tabel . Distribusi responden berdasarkan tingkat pendidikan

\begin{tabular}{|c|c|c|c|}
\hline No. & Pebdidikan & $(\mathrm{n})$ & $(\%)$ \\
\hline 1 & SD & 7 & 20.0 \\
\hline 2 & SLTP & 3 & 8.6 \\
\hline 3 & SMA & 10 & 28.6 \\
\hline 4 & S1 & 15 & 42.9 \\
\hline & Total & 35 & 100.0 \\
\hline
\end{tabular}

Sumber : Data Primer 2014

Berdasarkan table diatas didapatkan bahwa distribusi responden berdasarkan tingkat pendidikan, sebagian besar pendidikan responden tergolong tinggi yaitu S1 sebanyak 15 $(42,9 \%)$ orang, tingkat pendidikan SMA sebanyak 10 (28,6\%), SLTP sebanyak 3
$(8,6 \%)$ orang dan tingkat SD sebanyak $7(20,0 \%)$ orang.

4. Pekerjaan Responden

Berikut ini distribusi responden berdasarkan pekerjaan pasien yang di rawat di ruang Perawatan Anggrek Lantai II RSUD Polewali Mandar tahun 2014 dapat dilihat pada tabel berikut :

Tabel : Distribusi responden berdasarkan pekerjaan responden.

\begin{tabular}{|c|c|c|c|}
\hline No. & Pekerjaan & $(\mathrm{n})$ & $(\%)$ \\
\hline 1 & Bekerja & 22 & 62.9 \\
\hline 2 & Tidak Bekerja & 13 & 37.1 \\
\hline & Total & $\mathbf{3 5}$ & $\mathbf{1 0 0 . 0}$ \\
\hline
\end{tabular}

Sumber : Data Primer 2014

Berdasarkan tabel diatas didapatkan bahwa distribusi responden berdasarkan pekerjaan, dimana kategori bekerja sebanyak $22(62,9 \%)$ orang, dan kategori tidak bekerja sebanyak 13 $(37,1 \%)$ orang. a. Distribusi responden berdasarkan Orinetasi responden

Berikut ini distribusi responden berdasarkan orientasi responden yang di rawat di ruang Perawatan Anggrek Lantai II RSUD Polewali Mandar tahun 2014 dapat dilihat pada tabel berikut :

Tabel: Distribusi responden berdasarkan orientasi responden.

\begin{tabular}{|c|l|c|c|}
\hline No. & \multicolumn{1}{|c|}{ Orientasi Responden } & $(\mathrm{n})$ & $(\%)$ \\
\hline 1 & Mengerti & 25 & 71.4 \\
\hline 2 & Tidak Mengerti & 10 & 28.6 \\
\hline & Total & $\mathbf{3 5}$ & $\mathbf{1 0 0 . 0}$ \\
\hline
\end{tabular}

Sumber : Data Primer 2014

Berdasarkan tabel diatas responden mengerti sebanyak 25 didapatkan bahwa distribusi responden $\quad(71,4 \%)$ orang, tidak mengerti sebanyak berdasarkan orientasi, dimana $10(28,6 \%)$ orang. 
b. Distribusi responden berdasarkan tingkat kecemasan

Berikut ini distribusi responden berdasarkan tingkat kecemasan pasien yang di rawat di ruang Perawatan Anggrek Lantai II RSUD Polewali Mandar tahun 2014 dapat dilihat pada tabel berikut :

Tabel : Distribusi responden berdasarkan tingkat kecemasan responden.

\begin{tabular}{|c|c|c|c|}
\hline No. & Tingkat Kecemasan & $(\mathrm{n})$ & $(\%)$ \\
\hline 1 & Tidak Ada Kecemasan & 4 & 11.4 \\
\hline 2 & Kecemasan Ringan & 14 & 40.0 \\
\hline 3 & Kecemasan Sedang & 11 & 31.4 \\
\hline 4 & Kecemasan Berat & 6 & 17.1 \\
\hline & Total & $\mathbf{3 5}$ & $\mathbf{1 0 0 . 0}$ \\
\hline
\end{tabular}

Sumber : Data Primer 2014

Berdasarkan tabel diatas didapatkan bahwa distribusi responden berdasarkan kecemasan, kategori kecemasan yang paling banyak pada responden yaitu kategori kecemasan ringan sebanyak 14 (40,0\%), sedangkan kategori kecemasan yang sedikit yaitu tidak ada kecemasan sebanyak 4 $(11,4 \%)$

orang

\section{Analisa Bivariat}

Tabel hubungan orientasi dengan tingkat kecemasan responden

\begin{tabular}{|c|c|c|c|c|c|c|c|c|c|c|}
\hline \multirow[b]{2}{*}{ Orientasi } & \multicolumn{8}{|c|}{ Jam Tidur } & \multirow[b]{2}{*}{ Total } & \multirow[b]{2}{*}{$\%$} \\
\hline & $\begin{array}{l}\text { Tidak Ada } \\
\text { Kecemasan }\end{array}$ & $\%$ & $\begin{array}{l}\text { Cemas } \\
\text { Ringan }\end{array}$ & $\%$ & $\begin{array}{l}\text { Cemas } \\
\text { Sedang }\end{array}$ & $\%$ & $\begin{array}{c}\text { Cemas } \\
\text { Berat }\end{array}$ & $\%$ & & \\
\hline Mengerti & 4 & 11.4 & 6 & 17.1 & 10 & 28.6 & 5 & $\begin{array}{c}14 . \\
3\end{array}$ & 25 & 71.4 \\
\hline $\begin{array}{c}\text { Tidak } \\
\text { Mengerti }\end{array}$ & 0 & 0 & 8 & 22.9 & 1 & 2.9 & 1 & 2.9 & 10 & 28.6 \\
\hline \multirow[t]{2}{*}{ Total } & 4 & 11.4 & 14 & 40.0 & 11 & 31.4 & 6 & $\begin{array}{c}17 . \\
1\end{array}$ & 35 & 100 \\
\hline & \multicolumn{10}{|c|}{ Fisher's Exact Test : $\mathbf{p}=\mathbf{0 , 0 2 7}$} \\
\hline
\end{tabular}

Sumber : Data Primer 2014

Berdasarkan tabel tabulasi silang diatas didapatkan data bahwa kategori tertinggi pada kategori orientasi mengerti dengan kecemasan sedang sebanyak 10 responden $(28,6 \%)$ dan terendah pada kategori orientasi tidak mengerti dengan tidak ada kecemasan sebanyak 0 responden ( $0 \%)$.

Dengan menggunakan uji statistik fisher's exact test diperoleh nilai $p=0,027<\alpha 0,05$ maka dapat disimpulkan bahwa Ha diterima yang berarti terdapat hubugan antara orientasi dengan tingkat kecemasan pasien yang di rawat diruang Perawatan Anggrek Lantai II RSUD Polewali Mandar tahun 2014.

\section{PEMBAHASAN}

Berdasarkan data didapatkan bahwa distribusi responden berdasarkan orientasi, dimana 
responden mengerti sebanyak 25 $(71,4 \%)$ orang, dan tidak mengerti sebanyak $10(28,6 \%)$ orang.

Pasien saat masuk rumah sakit sebelum diberikan orientasi seringkali mengalami kecemasan, kecemasan ini tidak hanya dialami oleh pasien tapi juga oleh keluarga. Hal ini dapat disebabkan karena ketidak tahuan tentang kegiatan yang ada di rumah sakit dan memerlukan penjelasan lebih lanjut (Purwadarminta, 2009).

Kecemasan yang berlebihan dapat berdampak negatif pada pasien dimana pasien dapat memperlihatkan sikap bermusuhan, respon terhadap lingkungan menurun bahkan tidak ada samasekali sehingga sulit untuk diajak bekerjasama dengan perawat (Keliat, 2008). Pasien dengan tingkat kecemasan yang ringan sering ditanggulangi tanpa pemeriksaan yang serius, sebaiknya tingkat kecemasan yang sedang dan berat akan menimbulkan dua jenis mekanisme koping antara lain reaksi yang berorientasi pada tugas (adaptif) dan mekanisme pertahanan ego (maladaptif).

Berdasarkan tabel 4.6 diatas didapatkan bahwa distribusi responden berdasarkan kecemasan, kategori kecemasan yang paling banyak pada responden yaitu kategori kecemasan ringan sebanyak 14 (40,0\%), sedangkan kategori kecemasan yang sedikit yaitu tidak ada kecemasan sebanyak $4(11,4 \%)$ orang.

Kecemasan adalah respon emosional terhadap penilaian yang berkaitan dengan perasaan tidak pasti dan tidak berdaya. Keadaan emosi ini tidak memiliki objek yang spesifik. Kecemasan berbeda dengan rasa takut, yang merupakan penilaian intelektual terhadap sesuatu yang berbahaya (Stuart, 2006).

Kecemasan memiliki dua aspek yakni aspek sehat dan aspek membahayakan, yang bergantung pada tingkat kecemasan, lamanya kecemasan yang dialami dan seberapa baik individu melakukan koping terhadap kecemasan. Kecemasan dapat dilihat dalam rentang ringan, sedang, berat sampai panic (Videbeck, 2008).

Kecemasan adalah masalah yang bisa dialami oleh siapapun didunia ini. Terjadinya kecemasan ini biasanya saat stress atau masalah yang dialami seseorang tidak kunjung reda. Dalam penelitian ini menyatakan bahwa penyebab depresi para seseorang dihubungkan dengan ketidakmampuan atau berkurangnya kemandirian dalam beraktifitas dan oleh karena penyakit, umur, dan faktor psikososial.

Penelitian Helena Lenawati (2005) tentang tingkat kecemasan menunjukkan bahwa tingkat kecemasan pasien yang dirawat di Ruang Interna yang mengalami kecemasan ringan sampai sedang yaitu sebanyak 40 orang $(71,4 \%)$ yang terdiri dari cemas ringan sebanyak 12 orang $(21,4 \%)$, cemas sedang 28 orang (50\%). Sedang pasien yang tidak mengalami cemas sebesar 16 orang $(28,6 \%)$.

\section{Hubungan Orientasi dengan Tingkat Kecemasan}

Berdasarkan tabel tabulasi silang tabel 4.7 didapatkan data bahwa kategori tertinggi pada kategori orientasi mengerti dengan kecemasan sedang sebanyak 10 responden $(28,6 \%)$ dan terendah pada kategori orientasi tidak mengerti dengan tidak ada kecemasan sebanyak 0 responden $(0 \%)$. 
Dengan menggunakan uji statistik fisher's exact test diperoleh nilai $p=0,027<\alpha 0,05$ maka dapat disimpulkan bahwa Ha diterima yang berarti terdapat hubugan antara orientasi dengan tingkat kecemasan pasien yang di rawat diruang Perawatan Anggrek Lantai II RSUD Polewali Mandar tahun 2014.

Menurut Barbara (1996) dalam pelaksanakan orientasi yang optimal akan menimbulkan suatu pemahaman kepada pasien tentang keadaannya dan menghindarkan pasien dari persepsipersepsi negatif yang timbul akibat ketidak tahuan pasien tentang keadaannya (Asmadi, 2009).

Pemahaman terhadap suatu kerangka berfikir yang jelas akan menurunkan kecemasan dan sangat berguna bagi seseorang untuk menurunkan tingkat kecemasan sampai kepada kondisi yang ringan atau sedang. Pasien di Ruang Perawatan mengalami ketakutan pada sesuatu yang tidak dikenal dan prosedurprosedur yang mungkin menyakitkan hal tersebut kemungkinan sebagai penyebab yang paling umum dari kecemasan, selama pasien dirawat. Salah satu tujuan perawatan adalah dengan memberikan orientasi yang baik. Pasien yang menerima informasi dengan jelas akan dapat melakukan perawatan secara mandiri (Purwanto, 2012).

Menurut Carpenito (1995) yang dikutip oleh Asmadi (2009) menyatakan bahwa ketidakmampuan pasien beradaptasi karena perpisahan dengan keluarga, adanya perubahan kebiasaan yang rutin, lingkungan yang baru, prosedur tindakan yang menyakitkan dapat menyebabkan koping tidak efektif yang dapat dilihat dari penampilan perilaku yaitu menarik diri, bermusuhan dan tegang.

Dari uraian diatas menunjukkan bahwa orientasi berpengaruh terhadap tingkat kecemasan pasien. $\mathrm{Hal}$ ini dikarenakan pemberian orientasi menimbulkan penyesuaian pasien dengan lingkungannya yang dapat menurunkan tingkat kecemasan pasien.

Setelah dilakukan orientasi akan terjadi proses adaptasi pada pasien dengan tahap : kesadaran, tertarik, evaluasi, mencoba, menerima sehingga pasien dapat menyesuaikan diri dengan lingkungan yang baru.

Hasil penelitian ini sejalan dengan Helena Lenawati (2005) yang mana didapatkan data nilai rata-rata tingkat kecemasan sebelum diberikan orientasi adalah 1,21 dengan standar deviasinya 0,868 , nilai rata-rata tingkat kecemasan setelah diberikan orientasi mengalami penurunan yaitu 0,64 dengan standar deviasinya adalah 0,862 . Hasil uji statistik Wilcoxon Signed rank test menghasilkan signifikansi sebesar 0,001 berarti ada pengaruh orientasi terhadap tingkat kecemasan $p$

\section{KESIMPULAN DAN SARAN Kesimpulan}

Ada hubungan antara orientasi dengan tingkat kecemasan pasien di ruang perawatan Anggrek Lantai II dengan menggunakan uji Fisher's Exact Test adalah $=0.027$ dimana nilai $\mathrm{p}<$ 0,05 yang berarti bahwa ada hubungan untuk variabel tersebut.

\section{SARAN}

Kepala ruangan perlu memotivasi perawat yang jaga agar melaksanakan prosedur tetap terhadap kegiatan orientasi pada semua pasien yang baru masuk rumah sakit. 
Perawat hendaknya melaksanakan prosedur tetap program orientasi kepada setiap pasien baru sesuai dengan prosedur, sehingga pelaksanaan orientasi dapat optimal dan terjadi penurunan tingkat kecemasan pasien.

Penelitian lebih lanjut mengenai pengaruh orientasi terhadap tingkat kecemasan pasien dengan jumlah sampel yang lebih besar.

Prosedur tetap orientasi hendaknya dipasang di dinding ruangan agar mudah di lihat oleh perawat ruangan sehingga orientasi dapat dilaksanakan sesuai prosedur.

\section{DAFTAR PUSTAKA}

Asmadi (2009). Mengatasi Rasa Cemas. Surabaya : Putra Pelajar.

Arline (2007), Belajar Merawat di Bangsal Penyakit Dalam, Jakarta : Penerbit Buku Kedokteran EGC.

Bouwhuzen (2006), IImu Keperawatan Bagian I, Jakarta : Penerbit Buku Kedokteran EGC.

Depkes RI, 2012. 2011. Pedoman Pemantaaun Wilayah Setempat Kesehatan Perorangan. Jakarta : Direktorat Jenderal Bina Kesehatan Keluarga.

Hidayat, A. Aziz Alimul. 2007. Riset Keperawatan dan Teknik Penulisan IImiah. Jakarta : Salemba Medika.

Notoatmodjo (2010), Metodologi Penelitian Kesehatan, Jakarta, PT. Rineka Cipta. (2033), Pendidikan dan Perilaku Kesehatan. Jakarta, PT. Rineka Cipta.

Nursalam (2003), Konsep dan Penerapan Metodologi Penelitian IImu Keperawatan, Pedoman Skripsi, Tesis, Tesis, dan Instrumen
Penelitian Jakarta : Salemba Medika. 2011.

Konsep dan Penerapan Metodologi Penelitian IImu Keperawatan: Pedoman Skripsi, Tesis dan Instrumen Penelitian Keperawatan. Edisi Kedua. Jakarta: Salemba Medika.

Potter, Patricia A dan Perry Anne G, (2005). Buku Ajar Fundamental Keperawatan : Konsep, Proses, dan Praktik. Edisi 4. Jakarta : EGC.

Purwanto, Agung (2012), Pengaruh Orientasi terhadap Tingkat Adaptasi Psikologis Anak Pra Sekolah, Surabay : PSIK Unair.

Putra, ST (2004). Perkembangan Paradigma PNI Menuju Disciplines Hibrid. Makalah Simposium Nasional Perdana PNI, Pengembangan dan Penerapan PNI

Stuart , G. W. (2006). Principls and Practice of Psychiatris Nursing. St . Louis Missouri Mosby.

Suliswati. dkk. (2005), Konsep Dasar Keperawatan Kesehatan Jiwa. Jakarta: EGC.

Sugiyono. (2008). Statistika Penelitian dan Aplikasinya dengan SPSS 10.0 for windows, Bandung: Alfabeta.

Thalib. H (2006), Psikiater Manajemen Stress, Cemas dan Depresi, Jakarta : FKUI.

Tomb David A. (2004) .Buku Saku Psikiatri.Cetakan 1 edisi 6. Jakarta: EGC.

Videbeck, Sheila L. (2008). Buku Ajar Keperawatan Jiwa. Jakarta: EGC.I

Wahab, A, 2012. Pengantar Riset (Bidang Kesehatan, Kebidanan dan Keperawatan). Yogyakarta : Kutub Waca 